Journal of Environmental
Analysis and Progress
ISSN: $2525-815 \mathrm{X}$

\title{
Temaki de salmão: análise microbiológica e percentual de resíduos orgânicos
}

\section{Salmon temaki: microbiological and percentage analysis of organic residues}

Neide Kazue Sakugawa Shinohara ${ }^{\mathrm{a}}$, Indira Maria Estolano Macêdo ${ }^{\mathrm{a}}$, Ludmila Pereira de Oliveira ${ }^{\mathrm{b}}$, Maria do Rosário de Fátima Padilha ${ }^{a}$, Paulo Roberto Campagnoli de Oliveira Filhoc ${ }^{c}$ Eron Ferreira Campos $^{\mathrm{d}}$

${ }^{a}$ Universidade Federal Rural de Pernambuco-UFRPE, Departamento de Tecnologia Rural, Laboratório dos Alimentos e Laboratório de Microbiologia Ambiental, Rua Dom Manoel de Medeiros, SN, Dois Irmãos, Pernambuco, Brasil. CEP: 52171-900. E-mail: neideshinohara@gmail.com, indiramacedo@gmail.com, padilhamrf@gmail.com.

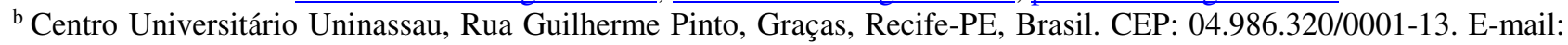
lud220@ hotmail.com.

${ }^{\mathrm{c}}$ UFRPE, Departamento Engenharia de Pesca e Aquicultura, Laboratório Tecnologia de Pescados, Rua Dom Manoel de Medeiros, SN, Dois Irmãos-PE, Brasil. CEP: 52171-900. E-mail: paulocoliveira79@ hotmail.com.

${ }^{d}$ Instituto Federal de Pernambuco-IFPE, Rua Sebastião Joventino, SN, Central Prédio Provisório (Fachuca), Destilaria, Cabo de Santo Agostinho-PE, Brasil. CEP: 54.510-110. E-mail: eronfes@ gmail.com.

A R T I C L E I N F O

Recebido 28 Dez 2018

Aceito 25 Jan 2018

Publicado 31 Jan 2018

\begin{abstract}
A B S T R A C T
The sushi has become a delicacy of great consumption in Brazil and in major world cities. The production is still handmade and associated with in natura consumption, are favourable conditions to trigger food outbreaks. They were acquired from companies that provide Atlantic Salmon (Salmo salar L.) to Japanese restaurants in Recife, three frozen salmon, whole and later portioned in: head; skin; fillet and fish residues (spine, fin, tail, gill and scale), to verify the bacteriological quality of fillet and percentage of inedible parts. This study evaluated the hygienic-sanitary conditions of Salmon Temaki marketed by 15 different specialized restaurants in the City of Recife. Tests were performed for the detection of coagulase positive Staphylococcus and Salmonella spp. in fillets and Temakis; and of total and thermotolerant coliforms and Vibrio parahaemolyticus in Temakis. The remainder as the head $(14.55 \%)$ and other residues $(21.75 \%) 36.31 \%$ of total inedible portions. Regarding the bacteriological evaluation of salmon fillets, no coagulase positive Staphylococcus and Salmonella spp. were found, proving that the fish of the suppliers surveyed are safe for in natura consumption, according to current sanitary legislation. As for Salmon Temakis, they are also in compliance with legislation, because no thermotolerant coliforms, coagulase positive Staphylococcus, Salmonella spp. and V. parahaemolyticus were detected. Total coliforms were found in the Temakis in the concentration of $3.6 \times 10^{2}$ to $2.57 \times 10^{3}$. However, it cannot be said that the salmon fillet is not suitable for consumption, since Resolution $n^{\circ} 12 / 2001$ does not determine that the detection be required; but it can be said that its presence indicates a poor hygienic-sanitary condition. The constant monitoring of Good Manipulation Practices is an indispensable tool for the safety and sustainability of a food so important in the human diet.
\end{abstract}

Keywords: Sushi, fish, food pathogen, visceral pollutant.

\section{R E S U M O}

O sushi tornou-se uma iguaria de grande consumo no Brasil e nas principais metrópoles mundiais. A produção ainda é artesanal e associada ao consumo in natura, são condições propícias para desencadear surtos alimentares. Foram adquiridos de empresas que fornecem Salmão do Atlântico (Salmo salar L.) para os restaurantes japoneses no Recife, três salmões congelados, inteiros e posteriormente porcionados em: cabeça; pele; filé e resíduos do pescado (espinha, nadadeira, cauda, guelra e escama), para verificação de qualidade bacteriológica do filé e percentual 
de partes não comestíveis. Nessa pesquisa foram avaliadas as condições higiênicosanitárias de Temaki de Salmão comercializado por 15 diferentes restaurantes especializados na Cidade do Recife. Realizou-se ensaios para detecção de Staphylococcus coagulase positiva e Salmonella spp. nos filés e nos Temakis; e de coliformes totais e termotolerantes e Vibrio parahaemolyticus nos Temakis. Foram encontrados como partes comestíveis $53,42 \%$ de filé e $10,27 \%$ de pele; o restante como a cabeça $(14,55 \%)$ e demais resíduos $(21,75 \%)$ totalizando $36,31 \%$ de porções não comestíveis. Quanto à avaliação bacteriológica dos filés de Salmão não foram encontrados Staphylococcus coagulase positiva e Salmonella spp., comprovando que os peixes dos fornecedores pesquisados se mostram seguros para consumo in natura, de acordo com legislação sanitária vigente. Quanto aos Temakis de Salmão, os mesmos também estão em conformidade com a legislação, pois não foram detectados coliformes termotolerantes, $S$. coagulase positiva, Salmonella spp. e $V$. parahaemolyticus. Foram encontrados coliformes totais nos Temakis na concentração de $3,6 \times 10^{2}$ a $2,57 \times 10^{3}$, entretanto não se pode afirmar que o filé do salmão esteja impróprio para o consumo, uma vez que a Resolução n ${ }^{\circ} 12 / 2001$ não determina a obrigatoriedade quanto à sua detecção; mas pode-se afirmar que sua presença indica condição higiênico-sanitária deficiente. O constante monitoramento das Boas Práticas de manipulação é ferramenta imprescindível para segurança e sustentabilidade de um alimento tão importante na dieta humana.

Palavras-Chave: Sushi, peixe, patógeno alimentar, poluente visceral.

Introdução

A cozinha japonesa era um dos tesouros escondido da culinária mundial, até que o sushi rompeu a casca e se tornou um fenômeno de consumo no início dos anos 90 , levando a expansão de restaurantes especializados e lojas de produtos orientais nas maiores metrópoles mundiais (Kasuko, 2010). Atualmente, o sushi conhecido como um ícone gastronômico do Japão apresenta aumento no consumo mundial, e no Brasil a preferência é o sushi de salmão, nas versões de niguirizushi e temaki (Padilha, Shinohara, Matsumoto, 2016; Shinohara et al., 2017).

O pescado é um produto de alto valor nutricional, fácil digestibilidade, altamente perecível $\mathrm{e}$, por isso, um excelente meio de cultura para o crescimento de microrganismos. Assim, a cadeia produtiva do pescado deve adotar boas práticas de manipulação, prevenindo a ocorrência de doenças transmitidas por alimentos (DTA) que podem evoluir para surtos alimentares (Braghiniet al., 2015; Santos et al., 2014). No caso do sushi e sashimi, são utilizadas preferencialmente lâminas de peixe in natura ou com breve cocção, o que torna o consumo dessa iguaria um risco de surto, caso não sejam atendidas as Boas Práticas de Manipulação.

Segundo Fukuoka (2009), o Temaki-zushi ou sushi temaki ou também conhecido como sushi enrolado à mão, é como um sanduíche bar selfservice ou no ambiente familiar que serve para reunir as famílias e amigos em volta da mesa, onde cada comensal prepara seu temaki. O arroz é depositado sobre folha de alga nori, recheado com vários ingredientes como hortaliças, filé de peixe in natura e crustáceos. Posteriormente, o fechamento é realizado em formato cônico, produzindo assim uma aparência de buquê de flores.
De acordo com Tonial et al. (2010), foi realizada uma pesquisa quanto ao teor de proteínas e lipídeos em filés de salmão in natura (Salmo salar L.), onde foram encontrados $17,89 \%$ de proteínas e $10,82 \%$ de lipídeos totais. Segundo esses autores o peixe de forma geral, incluindo o salmão, representa um alimento saudável por apresentar alto valor biológico quanto ao aporte proteico e de ácidos graxos essenciais, podendo ser considerado um alimento indicado para compor uma dieta saudável.

Entretanto, por sua composição em nutrientes e parâmetros intrínsecos favoráveis ao crescimento microrganismos, esta se mostra passível de contaminação por patógenos. O objetivo desse estudo foi avaliar a qualidade bacteriológica prevista na Resolução ${ }^{\circ} 12$ (Brasil, 2001) e o percentual de resíduos orgânicos gerados após a confecção do Temakizushi de salmão.

\section{Material e Métodos}

Local da amostragem e realização dos ensaios microbiológicos

As três amostras de Salmão do Atlântico e as 15 amostras dos Temakis de Salmão, foram adquiridas em duplicata na cidade do Recife em Pernambuco. Todos os ensaios microbiológicos foram realizados no Laboratório de Alimentos do Departamento de Tecnologia Rural, da Universidade Federal Rural de Pernambuco (UFRPE).

\section{Porcionamento do Salmão do Atlântico (Salmo salar L.) \\ Para a avaliação do percentual de cada} fração do salmão, foram adquiridos 3 (três) peixes congelados, inteiros de origem Chileno e sem as vísceras; obtido de empresa distribuidora de salmão registrada no Ministério da Agricultura e Pecuária (MAPA). Os peixes foram colocados em caixa de 
isopor com baterias de gelo e encaminhados para o local da análise. Após o descongelamento em refrigeração, os peixes foram separados em partes: cabeça, escamas, espinha, nadadeira, cauda, guelra, pele e filé. As amostras de filé foram imediatamente submetidas aos ensaios bacteriológicos, conforme determina a Resolução $\mathrm{n}^{\circ}$ 12/2001 da Agência Nacional de Vigilância Sanitária (ANVISA), para determinação do padrão microbiológico dos pescados in natura: Staphylococcus coagulase positiva e Salmonella spp.

Detecção e contagem de microrganismos no Temaki de Salmão

Foram adquiridas duas amostras de Temaki de Salmão em 15 restaurantes diferentes, especializados em culinária japonesa na cidade do Recife em Pernambuco. No momento da compra, foi solicitada a presença do responsável técnico ou gerente do estabelecimento, para obter a informação, se a empresa adotava o programa de coleta seletiva para resíduos orgânicos.

Foram realizados os ensaios para detecção de coliformes termotolerantes, Staphylococcus coagulase positiva, Salmonella spp. e $V$. parahaemolyticus, parâmetros biológicos determinados de acordo com legislação em vigor (Brasil, 2001). Para verificação da qualidade sanitária do manipulador/ambiente de produção, foi investigada a presença de coliforme total. As amostras foram processadas em duplicata e calculadas a média das Unidades Formadores de Colônias por grama (UFC.g ${ }^{-1}$ ).

Para a contagem de coliformes totais e termotolerantes (E. coli), Staphylococcus coagulase positiva e Salmonella spp. foram utilizados para a realização de teste rápido kits CompactDry®, respectivamente CompactDry TC®, CompactDry EC®, CompactDry XSA®, CompactDry SL®, metodologia aprovadas pela CodexAlimentarius, I.C.M.S.F., APHA, FDA, ISSO Standards e AOAC para ensaios microbiológicos de alimentos. Posteriormente, foram confrontados os resultados obtidos das amostras de filé e Temaki de Salmão frente às exigências da legislação vigente (Brasil, 2001). Para a detecção de $V$. parahaemolyticus foi empregado a ISO/TS 21872 (ISO, 2007).

Os resultados foram expressos em Unidade Formadora de Colônia por grama (UFC.g ${ }^{-1}$ ) para detecção de Salmonela spp., presença/ausência em $25 \mathrm{~g}$ de amostra do filé e Temaki de salmão.

\section{Resultados}

Foi observado que $36,31 \%$ do salmão representou perdas alimentares nos restaurantes, porque são considerados resíduos não aproveitáveis, ou seja, partes não comestíveis (Quadro 1). Foram encontradas, como partes comestíveis, uma média de $53,42 \%$ constituída por filé e $10,27 \%$ de pele; as demais partes, como a cabeça, corresponderam a $14,55 \%$ e outros resíduos a $21,75 \%$.

Quadro 1. Per capita e percentual da fração do Salmão do Atlântico (Salmo salar L.). Fonte: Autores (2017).

\begin{tabular}{|c|c|c|c|c|c|}
\hline Peixe & Peso (g) & Filé (g) & Pele (g) & $\begin{array}{c}\text { Resíduos (espinha, } \\
\text { nadadeira, cauda, } \\
\text { guelras e escama) (g) }\end{array}$ & Cabeça (g) \\
\hline 1 & 7.205 & 3.925 & 790 & 1.420 & 1.070 \\
\hline 2 & 8.380 & 4.310 & 845 & 2.030 & 1.195 \\
\hline 3 & 7.730 & 4.200 & 755 & 1.650 & 1.125 \\
\hline \pm Dp & 7,772 & 4,145 & 796,7 & 1,700 & 1,130 \\
\hline \multicolumn{3}{|c|}{$\begin{array}{c}\text { Percentual Médio da porção comestível } \\
\text { (Filé e Pele) - 63,69\% }\end{array}$} & $\begin{array}{c}\text { Percentual Médio de resíduo do Salmão } \\
36,31 \%\end{array}$ \\
\hline
\end{tabular}

A Tabela 1 descreve o padrão higiênico, segundo a Resolução $n^{\circ} 12$ da Anvisa aplicado nas amostras dos três salmões que foram porcionados e usados para a obtenção do filé, principal matériaprima na confecção do sushi, cujo principal recheio é o grupo dos peixes. Essa avaliação foi necessária para determinar a qualidade higiênica em filés do Salmão do Atlântico que são fornecidos para os restaurantes investigados, uma vez que a obtenção de postas de filés envolve muitas etapas de manipulação, ambiente refrigerado, uso de utensílios e água para a higienização correta em todas as etapas de produção. Esses padrões são baseados nas normas sanitárias preconizadas pela Vigilância Sanitária, a qual regulamenta a comercialização e produção de alimentos no território nacional.

As amostras se mostraram próprias para o consumo, pois não foi encontrada a presença de patógenos entéricos, nem em níveis acima dos limites permitidos por lei (Quadro 2). O padrão 
bacteriológico de 15 diferentes restaurantes especializados em culinária japonesa, na cidade do Recife em Pernambuco estão de acordo com os padrões exigidos pela legislação em vigor (Quadro 2).

Tabela 1. Padrão microbiológico do filé de Salmão in natura (Brasil, 2001). Fonte: Autores (2017).

\begin{tabular}{ccccc}
\hline $\begin{array}{c}\text { Peixes } \\
\text { (P) }\end{array}$ & $\begin{array}{c}\text { Staphylococcus } \\
\text { coagulase } \\
\text { positiva/gramas }\end{array}$ & $\begin{array}{c}\text { Valor de } \\
\text { Referência } \\
\text { RDC n 12/2001 }\end{array}$ & $\begin{array}{c}\text { Salmonella } \text { sp. } \\
\mathbf{2 5} \mathbf{g}\end{array}$ & $\begin{array}{c}\text { Valor de } \\
\text { Referência } \\
\text { RDC no } \\
\mathbf{1 2 / 2 0 0 1}\end{array}$ \\
\hline P1 & $<10 \mathrm{UFC} \cdot \mathrm{g}^{-1}$ & & Ausente & \\
P2 & $<10 \mathrm{UFC} \cdot \mathrm{g}^{-1}$ & $10^{3} \mathrm{UFC} \cdot \mathrm{g}^{-1}$ & Ausente & Ausente/25 g \\
P3 & $<10 \mathrm{UFC} \cdot \mathrm{g}^{-1}$ & & Ausente & \\
\hline
\end{tabular}

Quadro 2. Média dos resultados do padrão bacteriológico de Temaki de Salmão e valores de referência da legislação em vigor (Brasil, 2001). $\mathrm{R}$ = Restaurante Especializado em Cozinha Japonesa; SR: =sem referência na RDC 12 (Brasil, 2001). Fonte: Autores (2017).

\begin{tabular}{|c|c|c|c|c|c|}
\hline $\begin{array}{c}\text { Serviço } \\
\text { Alimentação }\end{array}$ & $\begin{array}{c}\text { Coliformes } \\
\text { totais } \\
\text { UFC. } g^{-1}\end{array}$ & $\begin{array}{l}\text { Coliformes } \\
\text { à } 45^{\circ} \mathbf{C} \\
\text { UFC. } g^{-1}\end{array}$ & $\begin{array}{l}\text { Salmonella } \\
\text { sp. (25g) }\end{array}$ & $\begin{array}{c}\text { Staphylococcus } \\
\text { coagulase } \\
\text { positiva } \\
\text { UFC.g } \\
\end{array}$ & $\begin{array}{c}\text { Vibrio } \\
\text { parahaemolyticus } \\
\text { UFC.g } \mathrm{g}^{-1}\end{array}$ \\
\hline $\begin{array}{c}\text { Valor de } \\
\text { Referência } \\
\text { RDC no } \\
12 / 2001 \\
\end{array}$ & SR & $10^{2}$ UFC. $g^{-1}$ & ausente & $1^{2}$ UFC. $g^{-1}$ & $10^{3} \mathrm{UFC} \mathrm{g}^{-1}$ \\
\hline $\mathrm{R} 1$ & $3,60 \times 10^{2}$ & $<10$ & ausente & $<10$ & $<10$ \\
\hline $\mathrm{R} 2$ & $1,0 \times 10^{2}$ & $<10$ & ausente & $<10$ & $<10$ \\
\hline R3 & 20 & $<10$ & ausente & $<10$ & $<10$ \\
\hline $\mathrm{R} 4$ & $2,57 \times 10^{3}$ & $<10$ & ausente & $<10$ & $<10$ \\
\hline R5 & $7,3 \times 10^{2}$ & $<10$ & ausente & $<10$ & $<10$ \\
\hline R6 & 40 & $<10$ & ausente & $<10$ & $<10$ \\
\hline R7 & $1,3 \times 10^{2}$ & $<10$ & ausente & $<10$ & $<10$ \\
\hline $\mathrm{R} 8$ & $3,6 \times 10^{2}$ & $<10$ & ausente & $<10$ & $<10$ \\
\hline R9 & 10 & $<10$ & ausente & $<10$ & $<10$ \\
\hline R10 & $<10$ & $<10$ & ausente & $<10$ & $<10$ \\
\hline R11 & 30 & $<10$ & ausente & $<10$ & $<10$ \\
\hline R12 & $<10$ & $<10$ & ausente & $<10$ & $<10$ \\
\hline R13 & $2,3 \times 10^{2}$ & $<10$ & ausente & $<10$ & $<10$ \\
\hline R14 & $3,5 \times 10^{2}$ & $<10$ & ausente & $<10$ & $<10$ \\
\hline R15 & $2,84 \times 10^{2}$ & $<10$ & ausente & $<10$ & $<10$ \\
\hline
\end{tabular}

\section{Discussão}

Segundo dados do Ministério da Pesca e Aquicultura (MPA), a média anual de consumo de pescado por habitante no país alcançou 11,17 quilos em 2011, nada menos do que $14,5 \%$ a mais em relação ao ano anterior. Assim, pode-se acreditar, com alguma margem de segurança, que, atualmente,
Coliformes totais foram encontrados nos Temakis de Salmão na concentração de $10 \mathrm{UFC}^{-1} \mathrm{~g}^{-1} \mathrm{a}$ $2,57 \times 10^{3} \mathrm{UFC}^{-\mathrm{g}^{-1}}$ (Quadro 2). 
passível de provocar surtos alimentares devido à veiculação de microrganismos patogênicos.

Nesse estudo, os peixes analisados não apresentavam vísceras, porque as empresas que comercializam o salmão congelado retiram o conteúdo intestinal para evitar o risco de contaminação cruzada frente à microbiota visceral. Segundo Craig (2012), os chefes devem usar apenas peixe congelado, pois esses protocolos de congelamento para os peixes destinados a produção de sushis, são padrões exigidos pelos regulamentos de saúde pública na comunidade internacional, para minimizar agravos à saúde.

Apesar de não ser usual na rotina alimentar do brasileiro, o consumo de pele de salmão está presente em restaurantes na forma de Sushi Skin, ou seja, pele de salmão grelhado crocante colocado sobre o bolinho de arroz acidificado, bastante apreciado pelos gourmets da culinária japonesa no Brasil. O que esses comensais propiciam é um melhor aproveitamento de um alimento tão nobre e fonte alternativa de alimento.

No estudo de Boscolo et al. (2012), os autores elaboraram uma ração incluindo resíduos da indústria de filetagem de tilápia, como fonte de proteína de origem animal para a alimentação de alevinos de lambari, na perspectiva do melhor aproveitamento da cadeia do pescado. Ao final do estudo, comprovou-se que essa ração não causou prejuízo no desempenho dos animais, podendo ser empregada em conjunto com a alimentação convencional para alevinos, minimizando os impactos de resíduos biológicos da indústria pesqueira.

Em outro estudo promovido por Vasconcelos-Filho et al. (2017), avaliando aspectos de rendimento corporal de espécies de pescado, mostrou-se de grande importância, pois forneceu dados sobre as partes comestíveis, bem como informações para o aproveitamento integral dos resíduos gerados, como a produção de silagem, farinha e óleo de pescado. Esses achados são fundamentais diante de cenários de insegurança alimentar junto às populações vulneráveis, e também colabora na perspectiva de redução dos resíduos orgânicos da pesca industrial e de restaurantes, pois estes se mostram fortes poluentes ambientais.

No presente estudo, os gestores dos estabelecimentos quando questionados sobre a destinação do lixo orgânico da empresa, em sua totalidade e não somente dos peixes e frutos do mar, responderam que estes eram bem acondicionados nas lixeiras e entregues ao sistema público municipal de coleta de lixo. Segundo Padilha et al. (2017), o aproveitamento integral dos alimentos se constitui em uma alternativa ecológica e econômica, visando a redução dos resíduos gerados em serviços de alimentação, que ainda apresentam nutrientes importantes.

No Brasil a Lei $\mathrm{n}^{\circ}$ 12.305/10 institui a Política Nacional de Resíduos Sólidos, que trata das diretrizes relativas à gestão integrada e ao gerenciamento de resíduos sólidos; às responsabilidades dos geradores e do poder público, prevê a implantação de sistema de compostagem para resíduos sólidos orgânicos e também a articulação com os agentes econômicos, sociais e formas de utilização do composto produzido. Portanto, a destinação adequada dos resíduos alimentares está previsto na Política Ambiental em todas as esferas da gestão pública, pois o acúmulo incorreto destes resíduos desencadeia um ambiente propício à proliferação de pragas; modificação das condições físicas, químicas e biológicas do solo e dos recursos hídricos; e disseminação de doenças nos homens e animais superiores.

Segundo Pires \& Ferrão (2017), a partir da compostagem é possível transformar resíduos orgânicos em fertilizantes orgânicos. No Brasil apesar de que mais de $60 \%$ da massa total dos resíduos gerados pela população e empresas produtoras de alimentos, são classificados como resíduos orgânicos, esse tipo de reciclagem ocorre em apenas $4 \%$ da fração orgânica gerada, de acordo com informes oficiais. Segundo a Fiocruz (2015), existe outro agravante ambiental, a maior parte desses resíduos no país ainda está sendo disposta em lixões, apesar de sua proibição de acordo com Lei de Política Nacional de Resíduos Sólidos de 2010, podendo cronificar a saúde pública pela disposição a céu aberto de forte poluente orgânico, sem devido isolamento subterrâneo e de superfície.

De acordo com a Resolução ${ }^{\circ} 12$ da Anvisa (Brasil, 2001), que normatiza parâmetros biológicos nos pescados in natura, esta resolução determina a investigação de Staphylococcus coagulase positiva por grama e Salmonella sp. em $25 \mathrm{~g}$ de peixe. Diante dos resultados obtidos, pode-se afirmar que as amostras se encontraram próprias para o consumo, pois não foi encontrada a presença de ambos esses patógenos entéricos ou em níveis acima dos limites permitidos.

Os resultados do padrão bacteriológico de 15 diferentes restaurantes especializados em culinária japonesa, na cidade do Recife em Pernambuco estão de acordo com os padrões exigidos pela legislação em vigor (Brasil, 2001). Estão em conformidade com o que preconiza a mesma, ou seja, quanto aos resultados encontrados para coliformes à $45^{\circ} \mathrm{C}$, Salmonella sp., Staphylococcus coagulase positiva e $V$. parahaemolyticus, todos os parâmetros investigados estão dentro das normas sanitárias, quando confrontado com os valores de referência da Resolução n 12 (Brasil, 2001). 
Segundo Suat Moi, Heng \& Tan (2017), surtos alimentares por $S$. aureus e casos de salmonelose foram associados a dois itens populares prontos para consumo: sushi e sashimi na Malásia. Este estudo investigou esses patógenos em 149 sushis e 51 sashimis, coletados em 14 estabelecimentos de varejo, incluindo supermercados, hipermercados, restaurantes e mercados noturnos ao ar livre. Os resultados confirmaram uma contaminação de $S$. aureus e Salmonella entérica na ordem de 42\% (84/200), confirmada por testes moleculares. A conclusão dos autores é que foi encontrada uma alta taxa de ocorrência de S. aureus e Salmonella entérica em sushi e sashimi na Malásia e justifica a necessidade de monitorar o processo microbiológico de alimentos para garantir a segurança alimentar dos consumidores.

Não se pode afirmar que os temakis pesquisados estivessem impróprios para o consumo, uma vez que legislação em vigor (Brasil, 2001) não determina a obrigatoriedade quanto à sua detecção. Entretanto, podemos afirmar que sua presença indica uma condição higiênico-sanitária deficiente, porque a presença deste grupo é decorrente de falhas no processo de higienização na fabricação. A deficiência pode ser oriunda da contaminação cruzada por utensílios, equipamentos, manipulador ou pela água de consumo, esta última, sem a devida comprovação laboratorial de potabilidade.

Segundo Kim et al. (2017), o coliforme total é um indicador de higiene do ambiente, útil para entender se estão implementadas as boas práticas, bem como, para mostrar alguma possível presença de patógenos, uma vez que pode vir associada com uma microbiota entérica. De acordo com SilvaJúnior, Ferreira e Frazão (2017), outro aspecto importante é a higienização das superfícies que entram em contato com diversas espécies de peixes, porque a microbiota normal que cada espécie de peixe carrega, pode variar de acordo com o habitat de captura, hábitos alimentares, manejo, entre outros aspectos, fator este, que pode estar levando à contaminação cruzada passíveis de provocar surtos alimentares.

Braghini et al. (2015), investigando 15 amostras de filé de sashimi de salmão adquiridos em cinco restaurantes na cidade de Maringá no Paraná, observaram contaminação por coliformes totais em 12 amostras $(80 \%)$. Os autores descrevem que essa contaminação por esse grupo de bactérias pode ter ocorrido na captura, transporte ou processamento realizado nos restaurantes investigados, ressaltando a grande importância quanto à correta higienização na linha de produção.

A ausência de bactérias patogênicas nos filés de Salmão e Temaki, não significa que não haja risco biológico para o comensal, pois segundo Santiago et al. (2013), as organizações de saúde mundiais devem estar atentas aos surtos de origem biológica, física ou química, decorrente da contaminação direta ou cruzada, devido a falhas da matéria-prima, fluxograma de produção até o consumo final do pescado. As fases na cadeia de produção estão expostas as contaminações em ambiente insalubre, da água sem comprovação de potabilidade e a saúde do manipulador. Os patógenos entéricos humanos mais amplamente distribuídos: Escherichia coli, Salmonella spp., V. parahaemolyticus e $S$. aureus, bactérias que são encontradas com frequência em peixes, camarões, moluscos bivalves, caranguejos, grupos de proteínas que fazem cada vez mais parte dos hábitos alimentares dos brasileiros, através do consumo de sushis e sashimis, podendo ser o responsável por desencadear um surto alimentar e evoluir para gastroenterite aguda ou crônica.

$\mathrm{Na}$ literatura, são escassos os estudos que informam sobre a presença de patógenos em sushis e sashimis, pois se acredita que a presença de microbiota acompanhante no arroz seja inibida pela presença de elevada concentração de ácido acético $(10 \%)$ e sacarose (10\%) na sua temperagem, promovendo uma diminuição do $\mathrm{pH}$ e da atividade de água, desfavorecendo o crescimento de bactérias, principalmente as patogênicas, as quais, na sua maioria, são fastidiosas. No entanto, o sushi pode conter elementos como uma variedade de peixes in natura, camarão, polvo, ovos e outros alimentos proteicos usados como recheios ou cobertura, o que pode limitar a ação do ácido acético e do carboidrato sobre o crescimento de patógenos. Deste modo, se torna imprescindível uma maior atenção na manutenção da cadeia de refrigeração em todo o processo de produção, para o controle do crescimento de diferentes grupos de microrganismos (Barralet et al., 2004; Kasuko, 2010).

\section{Conclusão}

O sushi recheado com peixe é um alimento que foi adotado por diferentes culturas alimentares no mundo e, de forma geral, é consumido com pouca ou nenhuma cocção. Foram encontrados valores dentro dos parâmetros exigidos pela legislação vigente, tanto para as amostras de Salmão do Atlântico como para os Temakis de Salmão. No entanto, valores de coliformes totais ressaltam a importância do constante monitoramento das condições higiênico-sanitárias em toda a cadeia produtiva, para garantir a segurança junto aos consumidores.

Devemos observar o percentual de porções não comestíveis do Salmão do Atlântico, que representa quase metade do peso total do peixe, 
partes essas, que se constituem em resíduos sólidos orgânicos que são gerados pelos restaurantes e que ainda são destinados à coleta pública, ocasionando contaminação e sem perspectiva breve de solução tecnológica e ações efetivas da gestão pública, quanto a mitigação do poluente orgânico gerado nos restaurantes especializados em culinária japonesa.

\section{Agradecimentos}

Ao Departamento de Tecnologia Rural da Universidade Federal Rural de Pernambuco.

\section{Referências}

ARTHO, C. V.; SAERANG, D. P. E.; RUMOKOY, F. S. 2017. Analytical Hierarchy Process of Consumer Preference on Japanese Food Restaurants in Manado Town Square (Case Studies on Ichiban Sushi, Marugameudon and Torico). Journal Berkalailmiahefisiensi, v. 17, n. 01, p. 1-8.

BARRALET, J.; STAFFORD, R.; TOWNER, C.; SMITH, P. 2004. Outbreak of Salmonella in Singapore associated with eating sushi. CDI, v. 28, n. 4 , p. 527-528.

BOSCOLO, W. R.; FEIDEN, A.; SIGNOR, A. A.; KLEIN, S.; BITTENCOURT, F.; CORRÊIA, A. F. 2012. Resíduos da indústria de filetagem de tilápia do Nilo (Oreochromis niloticus) na forma de farinhas e silagem para a alimentação de Lambari (Astiana x Bimaculatus). Revista Acadêmica, v. 10, n. 2, p. $189-195$.

BRASIL. 2001. Ministério da Saúde. Agência Nacional de Vigilância Sanitária (ANVISA). Resolução RDC no 12 de 02 de janeiro de 2001. Regulamento Técnico Sobre os Padrões Microbiológicos para Alimentos. Diário Oficial. Brasília, DF. 10 de janeiro de 2001.

BRASIL. Lei $\mathrm{n}^{\circ} 12.305$ de 02 de agosto de 2010 . Institui a Política Nacional de Resíduos Sólidos. Disponível http://www.planalto.gov.br/ccivil_03/_ato20072010/2010/lei/112305.htm. Acesso: 23 de agosto de 2017.

CRAIG, N. 2012. Fish tapeworm and sushi. Canadian family physician Médecin de famille canadien, MD CM CCFP, v. 58, n. 6, p. 654-658.

EVANGELISTA-BARRETO, N. S.; DAMACENA, S. S.; CARDOSO, L. G.; MARQUES, V. F.; SILVA, I. P. 2017. Condições higiênicos sanitárias e grau de frescor do pescado comercializado no mercado de peixe em Cachoeira, Bahia. Revista
Brasileira de Higiene e Sanidade Animal, v. 11, n. 1, p. 60-74.

FAO. 2016. The State of World Fisheries and Aquaculture. Contributing to food security and nutrition for all. Rome. 200p.

FIOCRUZ. Fundação Oswaldo Cruz. 2015. Apesar da proibição, lixões persistem como problema ambiental. Disponível

https://agencia.fiocruz.br/apesar-daproibi\%C3\%A7\%C3\%A3o-lix\%C3\%B5es-

persistem-como-problema-ambiental. Disponível em: 12 de out. 2017.

FUKUOKA, Y. 2009. Cozinha Japonesa. São Paulo: Marco Zero.

ISO. INTERNATIONAL ORGANIZATION FOR STANDARDIZATION. ISO/TS 21872-2:2007(E). 2007. Microbiology of food and animal feeding stuffs-Horizontal method for the detection of potentially enteropathogenic Vibrio spp. Parte 2: Detection of species other than Vibrio parahaemolyticus and Vibrio cholerae, v. 21872-2, $1^{\mathrm{a}} \mathrm{ed}$.

KASUKO, E. 2010. Culinária Japonesa: receitas especiais fáceis de fazer. São Paulo: Publifolha.

KIM, H. W.; HONG, Y. J.; JO, J. I.; HA, S. D.; KIM, S. H.; LEE, H. J.; RHEE, M. S. 2017. Raw ready-to-eat seafood safety: microbiological quality of the various seafood species available in fishery, hyper and online markets. Letters in Applied Microbiology, v. 64, n. 1, p. 27-34.

PADILHA, M. R. F., SHINOHARA, N. K. S., MATSUMOTO, M. 2016. Valor Nutricional de Nigiri Zuzhi. Nutrição em Pauta, v. 6, n. 30,p. 43-46.

PADILHA, M. R. F.; SHINOHARA, N. K. S.; FERREIRA, E.; MACEDO, I. M. E.; MACHADO, J.; CARVALHO-NETO, P. M. 2017. Formulation of morning product using food residues. Revista Geama, v. 3, n. 4, p. 210-215.

PETROSKI, L. P. S.; DIAS, R. C.; HRUBY, C.; PEREIRA, L.; TEIXEIRA, D. S. 2014. Análise microbiológica de temakis em um shopping na cidade de Salvador-BA. Revista de Educação Continuada em Medicina Veterinária e Zootecnia, v.12, n. 1, p.49-55.

PIRES, I. C. G.; FERRÃO, G. E. 2017. Compostagem no Brasil sob a perspectiva da 
legislação ambiental. Revista Trópica-Ciências Agrárias e Biológicas, v. 9, n. 01, p. 01-18.

PORTAL BRASIL. Disponível em: SILVA JUNIOR, A. C. S.; FERREIRA, L. R.; http://www.brasil.gov.br/economia-eemprego/2013/10/consumo-de-pescado-no-brasilaumenta-23-7-em-dois-anos. Acesso em 22 de agosto de 2017.

SANTIAGO, J. A. S.; ARAÚJO, P. F. R.; SANTIAGO, A. P.; CARVALHO, F. C. T.; VIEIRA, R. H. S. F. 2013. Bactérias patogênicas relacionadas à ingestão de pescados- Revisão. Arq. Cien. Mar, v. 46, n. 2, p. 92-103.

SANTOS, A. C. V.; LIRA,A.D. de; REIS,J. C.;COSTA, N. P.; SILVA, C. A.; ALBINATI,R. C. B.;SILVA,M. C. A. 2014. Avaliação higiênicosanitária e físico-estrutural dos estabelecimentos comerciais de pescado na cidade do SalvadorBA.Revista de Educação Continuada em Medicina Veterinária e Zootecnia, v. 12, n. 1, p. 51-59.

SHINOHARA, N. K. S.; MACEDO, I. M. E.; PADILHA, M. R. F.; SHINOHARA, G. M.; VASCONCELOS, M. L. M. B. 2017. Qualidade
Bacteriológica do Sushi de Salmão. Nutrição em Pauta, v. 7, n.37,p. 43-46. FRAZÃO, A. S. 2017. Avaliação da condição higiênico-sanitária na comercialização de pescado da feira do produtor rural do Buritizal, Macapá-Amapá. Life Style Journal, v. 4, n. 1, p. 71-81.

SUATMOI, P.; KEKHENG, C.; JINAI,T. TAN, J. A. M. A. 2017. Prevalence of Staphylococcus aureus and Salmonella enterica in ready-to-eat sushi and sashimi. Tropical Biomedicine,v. 34, n. 1, p. 45-51.

TONIAL, I. B.; OLIVEIRA, D. F.; BRAVO, C. E. C.; SOUZA, N. E.; MATSUSHITA, M.; VISENTAINER, J. V. 2010. Physical chemical characterization and lipid profile of salmon (Salmo salar L.). Alimentos e Nutrição, v. 21, n. 1, p. 93-98.

VASCONCELOS-FILHO, M. B.; OLIVEIRA, C. R. R.; MELO, C. C.; SILVA, P. M. A.; ANDRADE, H. A.; OLIVEIRA FILHO, P. R. C. 2017. Rendimento corporal do bagre marinho, Sciades herzbergii. Arq. Cien., v. 50, n. 1, p. 72-80. 